\title{
Ssciendo
}

Ethics \& Bioethics (in Central Europe), 2021, 11 (3-4), 153-162

DOI:10.2478/ebce-2021-0012

\section{Ethics of vaccination prioritization and compulsory vaccination: An integrative approach}

\author{
Martin O’Malley, ${ }^{1}$ Jürgen Zerth ${ }^{2}$ \& Nikolaus Knoepffler ${ }^{3}$
}

\begin{abstract}
Vaccine scarcity and availability distinguish two central ethics questions raised by the Covid-19 pandemic. First, in situations of scarcity, which groups of persons should receive priority? Second, in situations where safe and effective vaccines are available, what circumstances and reasons can support mandatory vaccination? Regarding the first question, normative approaches converge in prioritizing most-vulnerable groups. Though there is room for prudential judgement regarding which groups are most vulnerable, the human dignity principle is most relevant for prioritization consideration of both medical and non-medical issues. The second question concerning mandates is distinct from considerations about persons' individual moral duty to receive vaccines judged reasonably safe and critical for individual and public health. While there is consensus regarding the potential normative support for mandated vaccination, the paternalistic government intervention of vaccine mandates requires a high bar of demonstrated vaccine safety and public health risk. We discuss stronger and weaker forms of paternalism to deal with the Covid-19 pandemic from an "integrative" approach that integrates leading normative approaches. We argue against a population-wide compulsory vaccination and support prudential measures to 1) protect vulnerable groups; 2) focus upon incentivizing vaccine participation; 3) maintain maximum-possible individual freedoms, and 4) allow schools, organizations, and enterprises to implement vaccine requirements in local contexts.
\end{abstract}

Keywords: covid-19, vulnerable persons, prioritization, compulsory vaccination, dignity

\section{Introduction}

When the Covid-19 vaccines were developed, approved, and then available for distribution in early 2021, each national and regional medical agency had undergone the difficult task of establishing priority regimens for administering still scarce vaccines. These strategies implemented decisions to prioritize groups of people who were particularly at risk from Covid19 illness, who were in close contact with people at risk such as medical-health professionals and nursing-home care providers, and groups performing systems-relevant activities such as firefighters, police, and public service employees. For example, the US's National Academies published their recommendations after careful ethics review in a book-length work in October 2020 (NASEM 2020). Germany's recommendations outlining the ethical and legal principles for prioritization were likewise generated with the cooperation of the German Ethics Council, STIKO (Ständige Impfkommission), and the Robert Koch Institute in November 2020. Though the early indications of successful vaccine candidates were greeted with hope and relief, it was also evident that vaccines would remain a scarce resource. Nations engaged in competitive actions to secure vaccines with pre-orders from pharmaceutical companies that created clear beneficiaries and unfortunately disadvantaged regions. The EU, acting as a negotiating bloc for member nations, was relatively disadvantaged compared to the USA, Israel, and the United Kingdom. This is remarkable given that one of the vaccines (Pfizer-BioNTech's Comirnaty) was even developed and produced in Germany. In many developed countries there is now more vaccine than is needed, while less economically developed countries continue to experience vaccine scarcity.

Section one briefly describes integrative medical-ethics - an approach that additionally integrates aspects of health economic incentive logic. Section two explores the question of whether the actual distribution and the prioritization preferred in most countries is consistent

\footnotetext{
${ }^{1}$ Friedrich Schiller University Jena (Germany); martin.omalley@uni-jena.de; ORCID: 0000-0002-1481-5556

${ }^{2}$ SRH Wilhelm Loehe University of Applied Science (Germany); juergen.zerth@srh.de; ORCID: 0000-00026371-8672

${ }^{3}$ Friedrich Schiller University Jena (Germany); n.knoepffler@uni-jena.de; ORCID: 000-001-5143-849X
} 
with ethical standards and principles, and whether we should strive for different prioritization for future pandemics. Section three explores the question of compulsory vaccination - mandates - to promote community immunity to Covid-19 disease. How far should state paternalism go? To what extent can the individual's right to self-determination be restricted to limit dangers to the life and health of others?

\section{Ethics approach: Integrative medical ethics (IME)}

Our ethics approach begins with the fundamental claims of the Universal Declaration of Human Rights (UDHR, 1948) as well as the traditions of ethics reasoning rooted in that consensus framework document. The integrative ethics approach (IME) thus respects the individual, the unique dignity of each patient, and their basic human rights. With a goal of integrating leading ethics approaches where they are presenting consensus recommendations, IME includes the well-established four principles of Beauchamp and Childress (2019): autonomy, nonmaleficence, beneficence, and justice as fairness (Rawls, 1999; Daniels, 2008). Likewise deserving of attention and respect are the three fundamental values of Emanuel et al. (2020a, p. 1309): "benefiting people and limiting harm, prioritizing the disadvantaged, and equal moral concern". IME also integrates efficiency and other practical insights from the business-ethics approach "ordo-responsibility", which focuses on rule-finding processes that are fair, implementable, and optimally efficient in terms of limiting transactional burdens of regulatory systems (Pies, 2016; Knoepffler \& O’Malley, 2016; Ranisch et al., 2020). Here, we can also refer to health economics approaches that highlight aspects of incentive schemes and individual responsibility and accountability to promote self-protection activities (Hall, 2011). Hence, incentives schemes are often combined with specific forms of regulation intended to reduce negative externalities due to the spread of infections (Laxminaryan \& Malani, 2011). Like public health considerations, this article considers both single-actor and group decision-making processes of incentives and impacts to develop implementable rules that respect organizational structures and are consistent with long-range social goals of public health, well-being, and ethics goals.

\section{Fair and implementable prioritization of vaccines}

Community disease outbreaks categorized as pandemics pose a world-wide existential risk that is grave evidence of both international human interdependence as well as the importance of international solidarity to adequately deal with such risk. Accordingly, the WHO (2021) uses a guiding principle that "No one is safe until everyone is safe" in its ethical framework. Unreserved national prioritization is thus not only ethically objectionable, but also practically unsupportable, especially when many countries are dealing with woeful shortages of basic medical infrastructure as well as intensive care beds and ventilators. The WHO (2020a) stresses the principle of "global equity" to "ensure that vaccine allocation considers the special epidemic risks and needs of all countries; particularly low-and middle-income countries." This principle corresponds to the justice concept advocated by IME that considers equity principles together with teleological goals of achievable social improvement (Knoepffler, 2021, p. 77).

This approach is also close in many respects to the influential "Fair Priority Model" (FPM) outlined in Emanuel et al. (2020a) in the journal Science in September 2020. ${ }^{4}$ When discussing fairness in medical prioritization, harm is understood in terms of reversibility, gravity, and potential for compensation. Three values are particularly relevant:

1. benefiting people and limiting harm,

2. prioritizing the disadvantaged, and

3. maintaining equity, thus, equal moral concern.

\footnotetext{
${ }^{4}$ The following paragraphs include sections from Knoepffler (2021, pp. 300-303).
} 
A person's death represents the greatest damage because it is at the same time irreversible and the deceased person cannot be compensated. Harms incurred from a recovered illness are often significant and difficult to compensate. And there are ancillary harms that include diminished education progress, economic damage, and lost opportunity costs.

For these reasons, Emanuel et al. (2020a) proposes the following measures of prioritization while avoiding problematic rationing logics. The IME approach more prominently emphasizes dignitarian ethics reasoning, but there is much overlap between the FPM and the IME. Especially important is the understanding of justice as fairness and the commitment to prioritization rather than rationing for life-threatening diseases. This raises questions regarding terminology.

Rationalization is the judicious and ethically obligated form of discerning the most efficient and effective medical management in a context of scarcity (cf. Knoepffler \& Daumann, 2018, p. 107). Rationalization can be understood as a reasonable and therefore compelling approach that saves valuable resources in a scarcity context while providing basic and needed services and therapies according to evidence-based principles.

"Rationing is used, in contrast to rationalization, to describe medical decision-making reasoning in a scarcity context that limits services or therapies despite well-established medical need or evidence-based benefits, even though in principle, all persons have a right to that service or therapy" (Knoepffler, Zerth \& O’Malley, 2019).

Prioritization, in distinction to rationing, describes "the systematically justified establishment of rankings - in healthcare, the drawing up of ranking lists, or league tables, of medical interventions" (Deutscher Ethikrat, 2011, p. 22). Prioritization indicates that certain treatment regimens are preferred to other treatment regimens. Here, a treatment regime is not rationed, i.e. only allocated to some, although others would also have the same entitlement, but the prioritization treats all comparably affected persons equally. This means that the treatment measures are the same for all "same" cases. In principle, Emanuel et al. (2020a), as well as the WHO and the German Ethics Council, are using this concept of prioritization with its embedded transnational perspective.

The FPM presents three phases for implementation where national priorities are legitimate to the degree that community infections can be prohibited from increasing. National partiality is ethically justified in situations of continuing disease acceleration. But once the domestic rate of transmission (Rt value) falls below 1, that means that a nation's infection levels are decreasing, national partiality is no longer justifiable, and fairness priority conditions (FPM) apply. The first phase indicates participating in an international distribution program giving priority to vaccinate persons who still have many years of life ahead of them. In this first phase, poorer countries with a high proportion of young people benefit. To provide a stable and transparent method of adjudicating priority, the FPM uses a matrix of "Standard Expected Years of Life Lost (SEYLL)," i.e., a reasonable expectation of expected years lost by infection. This distributive justice analysis is first relevant for distributing vaccines on the national levels and is not a matter of choosing which specific persons either receive or are denied vaccines. This distributive system provides policymakers with an equity-based decision-making logic to optimally protect against death and the harms caused by disease. Individual nations would have the responsibility to distribute vaccines to individuals using evidence-based analysis.

Phase one aims to reduce premature deaths using the SEYLL metric, which indicates that all other variables being equal, younger persons with more expected years to live have priority over older persons. This preference of the young over the old is justified with an argument that all persons, including the elderly, are considered equally and consistent with their human dignity. "It integrates the aims of limiting harm and of prioritizing the least advantaged... using a standard metric used in global burden-of-disease calculations" (Emanuel et al., 2020). Vaccine priorities do not deny persons their dignity, but rather gives priority to those in times 
of scarcity who are most likely to have the greatest benefit on an individual level. And on a national level, it gives priority to most disadvantaged nations.

In the second distribution phase, vaccine prioritization considers economic and social deprivations as well as mortality. So, in addition to minimizing SEYLL, issues of poverty are included into the distribution logic. Only in the third phase is the aim of ending community spread of disease infection. The following distribution prioritization would then result:

\begin{tabular}{|l|l|l|l|}
\hline \multicolumn{1}{|c|}{ Phase \& Aim } & \multicolumn{1}{|c|}{ Relevant Metric } & \multicolumn{1}{c|}{ Values } & \multicolumn{1}{c|}{ Prioritization } \\
\hline $\begin{array}{l}\text { Phase 1: Reduction of } \\
\text { premature deaths }\end{array}$ & SEYLL & $\begin{array}{l}\text { Prevent harm; human } \\
\text { life value; equity }\end{array}$ & $\begin{array}{l}\text { Countries with highest } \\
\text { potential SEYLL }\end{array}$ \\
\hline $\begin{array}{l}\text { Phase 2: Reduction of } \\
\text { ancillary harms }\end{array}$ & $\begin{array}{l}\text { Reduction of SEYLL, } \\
\text { poverty, national } \\
\text { economic well-being }\end{array}$ & Social Equity & $\begin{array}{l}\text { Countries most } \\
\text { poverty-impacted }\end{array}$ \\
\hline $\begin{array}{l}\text { Phase 3: Return to } \\
\text { health }\end{array}$ & $\begin{array}{l}\text { Ranking transmission } \\
\text { rates }\end{array}$ & $\begin{array}{l}\text { Prevent harm, dealing } \\
\text { with worst-impacted }\end{array}$ & $\begin{array}{l}\text { Countries with highest } \\
\text { transmission rates }\end{array}$ \\
\hline
\end{tabular}

Fair Priority Model (FPM) Table, derived from Emanuel et al., 2020a

But who are the worst off when it comes to Covid-19? A look at the prioritization criteria as recommended by STIKO, German Ethics Council, \& Leopoldina helps here:

- "Prevention of severe courses of Covid-19 (hospitalization) and deaths.

- Protection of persons with an especially high work-related risk of exposure to SARS-CoV-2 (occupational indication).

- Prevention of transmission and protection in environments with a high proportion of vulnerable individuals and in those with a high outbreak potential" (German Ethics Council \& Leopoldina, 2020, p. 3).

FPM presents transnational responsibilities exclusively within a distributive justice frame, such that an available scare resource (vaccine doses) ought to be divided among nations. In contrast, the IME concept of fairness integrates incentive considerations at the resource generation stage as well as distribution stage. Individual states have a responsibility to provide vaccines for their citizens, obviously. Emanuel et al. (2020a) argues that richer states should show extensive solidarity with poorer states by sending them a greater portion of scarce vaccines. These poorer nations are burdened by not only health impacts, but also by ancillary economic, social, and political harms. Richer countries, by contrast, have capacities to use alternative infection-avoiding measures. Both the FPM and IME regret that vaccination distribution in 2021 reflects marginal transnational solidarity. And IME would advocate creative national approaches of domestic partiality if that was linked with accelerated benefits for situations of poorer countries. With this "difference principle" logic, richer nations would be incentivized to accelerate vaccine development, production capacities, and patent negotiations in ways that more adequately reflect the global threat posed by not only the Covid 19 pandemic, but also future pandemic risks. Studies by the Rand Institute show how important transnational solidarity would be even if the richer states were acting in self-interest:

"Vaccine nationalism could lead to the unequal allocation of Covid-19 vaccines and cost the global economy up to $\$ 1.2$ trillion a year in GDP terms. Even if some countries manage to immunize their populations against the virus, if the virus is not under control in all regions of the world, there will continue to be a global economic cost associated with Covid-19. If the poorest countries cannot access vaccines the world would still lose about $\$ 153$ billion a year of GDP. The EU would lose about $\$ 40$ billion a year; the US could lose $\$ 16$ billion; and the UK between $\$ 2$ billion and $\$ 10$ billion" (Rand.org, 2020).

There is also another challenge: Although enough vaccine is available in some countries such as the USA or Germany, many people refuse to be vaccinated. Against this background, 
what measures are ethically necessary to ensure that as many people as possible can be vaccinated? Should there be compulsory vaccination?

\section{Compulsory vaccination}

The dispute as to whether there should be compulsory vaccination is not new. There was resistance already in 1807 when Bavaria promulgated its mandate for compulsory vaccination against smallpox. And it was not until 160 years later, in 1967, that international consensus backed the WHO's global program of vaccination to effectively eliminate smallpox disease. Wehrle (1980) notes the enormity and complexity of this effort, which required "administrative leadership and imaginative approaches" to stay a course based upon sound epidemiological principles. These international efforts were suspended in 1976 when smallpox no longer posed a threat.

There are important differences between the smallpox and Covid 19 pandemics - smallpox was more life-threatening and vaccine development is more reliable today - yet historical antivaccination arguments bear important similarities with the present situation (Bayerischer Rundfunk, 2021). There were conspiracy theories that cowpox would turn people into cows. There was talk of a "incineration of the blood" (Eckart, 2017, p. 169). Now, conspiracy theories claim that Covid-19 vaccinations would reduce fertility or that, along with this vaccination, people would be implanted with monitoring chips.

Serious concerns about vaccines, then as now, are about associated risks or side effects. Public figures and medical professionals should be able to dispel fears of very-low risks associated with today's vaccines. However, communication about risk is notoriously difficult and public health and government officials struggle to translate scientific analysis in ways that are understandable and convincing (NASEM, 2021). Given the significant number of persons who are not receiving available vaccines, and the enormous health and social costs associated with community infections among non-vaccinated populations, the question arises whether a Covid-19 vaccination should also be made compulsory, analogous to the previously mandatory smallpox vaccination. Only persons with reasonable medical justification would then be exempt from compulsory vaccination.

Economic analysis of opportunity costs offers insights into how we might understand the present public health situation. Opponents of vaccination reject the comparison between smallpox and Covid-19 because smallpox was much more dangerous than Covid-19. The mortality rate for untreated smallpox was roughly 30 percent for all population groups, largely regardless of age. For Covid-19, the mortality rate is closer to one percent, with older people having a much higher risk. Children and adolescents are at very low risk of dying from Covid19. Opponents of vaccination argue using basic rights claims such as their right to selfdetermination over their own body - a normative argument. Opposition to vaccination also reflects health economic analysis that, from the perspective of some individual citizens, the risks of the pandemic are basically acceptable.

Economic models analyze individual and social incentives, as well as the impacts of individual and social actions. Vaccination willingness has expected costs on the individual as well as social level (on vaccination propensity, see Laxminarayan \& Malani, 2011, p. 191f). The social effects of increasing vaccination coverage are compared with the individual "expense costs" from an ideal-typical, individual point of view. The perception of individual expected costs thus represents a decisive factor as to whether the social costs are underestimated in the expected benefits due to the positive externality of growing community ("herd") protection.

In other words: individuals assess the personal costs of their own vaccination against the expected benefit effects for themselves and for society. If individuals interpret vaccination as a probable personal net-loss in terms of risk costs, they are more likely to be skeptical or reject vaccination. With a view to preventive behavior, Cohen and Mooney use the distinction 
between utility in use and utility in anticipation to describe this reality (Cohen \& Mooney, 1984). Covid-19 vaccines are seen by people as offering a relatively minor personal preventative benefit, which involves an investment (cost) in time, minor disruptions from vaccination (arm pain, fever-like symptoms), and small risks of side effects. So, while there are practical benefits of vaccinations, people's expectations and priorities are culturally impacted and relevant to vaccination willingness (Zerth, 2014, p. 307f). In short, the expectation of an induced benefit from a prevention or vaccination must be justified by the directly effective assessments of the benefit situation or potential benefit restriction caused by the vaccination. Even if the side effects of vaccinations appear to be largely controlled, this ambiguity of benefit perspectives should not be ignored, at least when it comes to the question of the appropriate regulatory design.

Covid-19 vaccines have demonstrated effectiveness in building community immunity in real-world conditions according to the CDC in the USA, RKI in Germany, and national monitoring agencies worldwide. Analysis of risks associated with the vaccines is limited by the relatively short timeline of their use compared with previous vaccines with many years of safety histories (cf. Olliaro et al., 2021). Nevertheless, there is already sufficient data available to show that, for individuals, in situations of even minimal community infections, Covid-19 infection risks are significantly higher than risks associated with vaccination. The problem is that vaccination opponents overestimate their own personal costs, underestimate their personal risks, and generate social costs of expanding the size and endurance of the pandemic.

In addition to risk analysis, there are normative arguments for avoiding vaccines, often made using rights language and specifically with reference to self-determination. People who refuse vaccination for ideological reasons have an adverse effect on the community immunity that protects particularly vulnerable people, for example persons with compromised immune systems who cannot benefit from vaccines and are particularly impacted by disease. In addition to this harm to social welfare, they take advantage of social benefits in the event of illness. That is, they receive medical treatments and burden health systems without incurring financial cost. In addition, their behavior has knock-on impacts of increasing risk of further infections while diminishing available healthcare opportunities. Widespread infections and associated mitigation efforts impose dramatic social costs through mandated distance learning for young people, psychological harms from lockdowns, and economic disruptions. In terms of environmental and economic policy, one would say that their behavior creates external effects for which they do not accept responsibility. In other words: they exploit the solidarity of society.

This directs attention to the overriding questions of socially acceptable responsibility for individual actions and non-action (refusal to vaccinate) in the light of expected benefits and cost effects for the social level. An "emission model" of vaccination refusal, which can be classified as a phenotypical idea of a responsible behavior in appropriate contexts of actorrelated, society-related externalities, challenges the question of the allocation conditions of individual and social responsibility. This discussion brings a clarifying focus to the perspective dilemma of "bonum personal" versus the "bonum commune". Public health policy must respect persons' perspectives, rights, and responsibilities while achieving common good aims.

The IME approach, as integrative, builds upon already well-established social and ethical foundations to not only consider normative principles and action-bounding rules, but also seeks to propose action scenarios and rule frameworks that optimally achieve social goals. Even when viewed from the perspective of personal cost/benefit analysis, an otherwise healthy person who refuses the Covid-19 vaccination violates the duty of care because they are exposing themselves to a dangerous disease. Condemning anti-social action may be warranted, but hardly helpful. So, the question is raised: Should the state introduce a compulsory Covid-19 vaccination analogous to the former smallpox vaccination? Turkmenistan was the first country in the world to implement compulsory vaccination against Covid-19 on July 7, 2021. Many countries' democratic forms of government might not permit following Turkmenistan's example. 
Compulsory vaccination interventions in free constitutional states would stir public resistance and complaints of state paternalism - the father state knows better what is good for the individual than they do themselves.

Thus, we must consider efficiency potentials of various levels of government-mandated vaccination programs that might cause social disruption and thereby have marginal effect. It would be a political approach to internalizing external effects, but the approach directly raises questions of normative and political legitimacy: Who is responsible for these partial interventions that impact personal self-determination rights? And who can enforce these interventions? Some states have already made such an obligation for certain professional groups. For example, in February 2021, the Vatican State made vaccination compulsory for its 5000 employees by decree. Anyone not complying must expect employment termination. France announced similar measures for healthcare workers and public protests already show how difficult this measure is to implement.

A different approach avoids widespread government mandates, but carves out legal protection for schools, organizations, and enterprises to implement vaccine requirements in specific contexts that can respond to local needs. The practical logic of this approach is to allow individuals the freedom to either choose or refuse the vaccine, but to recognize, first, the need for safe community space and, second, the legitimacy of providing and enforcing conditions insuring that safe space. In principle, this is no different from the licensing authority exercised to insure safe automobile traffic on public roads. Persad and Emanuel argue that licenses "should be compared to the alternatives of enforcing strict public health restrictions for many months or permitting activities that could spread infection, both of which exacerbate inequalities and impose serious burdens" (Persad \& Emanuel, 2020, p. 2241). Non-vaccinated persons pose a risk to others, and while prudence would council against the imposition of mandates, persons posing a risk to public health would have the burden to show that they are not presently Covid-19 infected.

Quite a few countries have introduced restriction rules that require certification of 1) vaccination; 2) Covid-19 recovery; or 3) a recent negative result from a Covid-19 infection test. In Germany, these " $3 \mathrm{G}$ rules" are used by enterprises to insure safe public and workplace spaces. Some states are adopting stricter $2 \mathrm{G}$ rules requiring vaccination or timely tests. With such rules, reliable documentation of "risk-free status" gains importance for local and wider mobility. Vaccination "passports" make it possible for vaccinated persons to participate in life activities (school, work, leisure) among other persons who pose no elevated risk. The social perspective has priority over the individual perspective for determining rules regarding licensing to operate motor vehicles and wearing seatbelts. Individuals are not left to their own judgment regarding their risk status in public spaces. Likewise, the social perspective has priority for determining risk status of non-vaccinated persons. For such persons to enjoy unrestricted access to public spaces, they must demonstrate their non-risk status using publicly certified documentation. The financial and time costs for attaining documentation, through testing or whatever, could potentially be a burden that incentivizes pro-social outcomes (see Cassel \& Ulrich, 2021, p. 5).

Another alternative is to give incentives for vaccination that are perhaps non-obvious. This form of softer paternalism is also referred to as "nudging" in behavioral economics (Thaler \& Sunstein, 2011). For example, the former president of the Bayern Munich soccer club, Uli Hoeneß, invited people to an event where sausages were free of charge and there was also the option of vaccination. The possibility of boosting vaccination readiness through direct financial incentives may also be considered. Such experimentation is best left to local decision makers to exercise their prudence based upon specific cultural and community-infection conditions. 


\section{Conclusion}

The IME approach attempts to integrate leading ethics schools of thought in a way that respects legitimate worldview, philosophical, and religious differences, and which realizes that public health policies are most effective in meeting their goals when they conform to normative principles that demonstrably prioritize human dignity and enjoy public consensus. We argue against a wide-population compulsory vaccination and support prudential measures to 1) protect vulnerable groups; 2) focus upon incentivizing vaccine participation; 3) maintain maximum-possible individual freedoms; and 4) allow local contexts of schools, organizations, and enterprises to implement vaccine requirements in ways that are optimally designed for those contexts. While there is consensus regarding the potential normative support for mandated vaccination, the paternalistic government intervention of vaccine mandates requires a high bar of demonstrated vaccine safety, public health risk, and potential social acceptance.

Public health policies should be made at the most-local social level to be most fitting and effective for specific regional public health risks. This is a simple principle of practical reasoning or prudence. The present ethics analysis supports local decision makers by making it clear that it is ethically acceptable, in situations where vaccines are generally available and proven to be safe, to require non-vaccinated persons to not pose an avoidable risk to public health. It is ethically acceptable to require non-vaccinated persons to demonstrate that they are safe (not Covid-19 positive) in some minimally intrusive but reliable certification. And there is no moral reason - though there may be practical ones - for vaccinated persons to bear burdens created by other persons' non-compliance with public health recommendations. It is fair to frame individual cost-benefit incentives so that the benefit of getting vaccinated will be subjectively assessed higher than the assumed personal costs and disutilities. From a moralphilosophical point of view, the "realism" of incentive discussions is perhaps disappointing in presuming persons acting for selfish motives. The IME approach respects individual persons as moral subjects and bearers of human dignity, and the approach also respects the realities of subjective self-interest behavior within complex societies. The integrative approach does not treat persons as only homo economicus, but it respects the insights that such an approach brings to the public health rules we need to achieve reasonable goals of social flourishing.

\section{References}

BAYERISCHER RUNDFUNK (2021): Pocken, Polio und Corona. [online] [Retrieved August 26, 2021] Available at: https://www.br.de/wissen/impfung-pocken-polio-corona-impfgegnerimpfpflicht-104.html

CASSEL, D. \& ULRICH, V. (2021): Corona-Impfstoffe im Überfluss - was dann? In: Wirtschaftsdienst, 101(4), pp. 1-8.

COHEN, D. \& MOONEY, G. (1984): Prevention goods and hazard goods - a taxonomy. In: Scottish Journal of Political Economy, 31(1), pp. 92-99.

DANIELS, N. (2008): Just health: Meeting health needs fairly. Cambridge: Cambridge University Press.

DEUTSCHER ETHIKRAT (2011): Medical benefits and costs in healthcare: The normative role of their evaluation. Opinion. Berlin: German Ethics Council.

ECKART, W. (2017): Geschichte, Theorie und Ethik der Medizin [History, theory and ethics of medicine $], 8^{\text {th }}$ ed. Berlin: Springer.

EMANUEL, E. J. et al. (2020a): An ethical framework for global vaccine allocation. In: Science, 369(6509), pp. 1309-1312.

EMANUEL, E. J. et al. (2020b): Fair allocation of scarce medical resources in the time of Covid-19. In: New England Journal of Medicine, 382(21), pp. 2049-2055. 
HALL, J. (2011): Disease prevention, health care, and economics. In: S. Glied \& P. Smith (eds.): The Oxford handbook of health economics. Oxford: Oxford University Press, pp. 555577.

KNOEPFFLER, N. (2021): Den Hippokratischen Eid neu denken. Eine Medizinethik für die Praxis [Rethinking the Hippocratic oath. Medical ethics for the practice]. Freiburg: Karl Alber. KNOEPFFLER, N. \& DAUMANN, F. (2018): Gerechtigkeit im Gesundheitswesen [Justice in healthcare], $3^{\text {rd }}$ ed. Freiburg: Karl Alber.

KNOEPFFLER, N. \& O'MALLEY, M. (2016): An ordonomic perspective in medical ethics. In: C. Luetge \& N. Mukerji (eds.): Order ethics: An ethical framework for the social market economy. Cham: Springer, pp. 311-328.

KNOEPFFLER, N., ZERTH, J. \& O'MALLEY, M (2019): Prioritization not rationing in cancer care. In: E. Walter (ed.): Regulatory and economic aspects in oncology. Cham: Springer, pp. 189-205.

LAXMINARYAN, R. \& MALANI, A. (2011): Economics of infectious diseases. In: S. Glied \& P. Smith (eds.): The Oxford handbook of health economics. Oxford: Oxford University Press, pp. 189-205.

NASEM (NATIONAL ACADEMIES OF SCIENCES, ENGINEERING, AND MEDICINE) (2020): Framework for equitable allocation of Covid-19 vaccine. Washington, DC: The National Academies Press.

NASEM (NATIONAL ACADEMIES OF SCIENCES, ENGINEERING, AND MEDICINE) (2021): Understanding and communicating about Covid-19 vaccine efficacy, effectiveness, and equity. Washington, DC: The National Academies Press.

OLLIARO, P., TORREELE, E. \& VAILLANT, M. (2021): Covid-19 vaccine efficacy and effectiveness - the elephant (not) in the room. In: The Lancet Microbe, 2(7), pp. e279-e280. [online] [Retrieved August 26, 2021] Available at: https://doi.org/10.1016/S26665247(21)00069-0

PERSAD, G. \& EMANUEL, E. J. (2020): Immunity-based licenses (“immunity passports"). In: JAMA, 323(22): pp. 2241-2242.

PIES, I. (2016): The ordonomic approach to order ethics. In: C. Luetge \& N. Mukerji (eds.): Order ethics: An ethical framework for the social market economy. Cham: Springer, pp. 1935 .

RAND.ORG (2020): Covid-19 and the cost of vaccine nationalism. [online] [Retrieved August 25, 2021] Available at: https://www.rand.org/randeurope/research/projects/cost-of-covid19vaccine-nationalism.html

RANISCH, R. et al. (2020): Ordo-responsibility for germline gene editing. In: The CRISPR Journal, 3, pp. 37-43.

RAWLS, J. (1999): A theory of justice, revised edition. Oxford: Oxford University Press.

STIKO, Deutscher Ethikrat \& Leopoldina (2020): How should access to a Covid-19 vaccine be regulated. Position paper. [online] [Retrieved August 25, 2021] Available at: https://www.ethikrat.org.

THALER, R. \& SUNSTEIN, C. (2011): Nudge: Wie man kluge Entscheidungen anstößt. Berlin. Ullstein Verlag.

WEHRLE, P. (1980): A reality in our time: Certification of the global eradication of smallpox. In: The Journal of Infectious Diseases, 142(4), pp. 636-638.

WHO (2020a): Values framework for the allocation and prioritization of Covid-19 vaccines. World Health Organization. [online] [Retrieved June 17, 2021] Available at: https://www.who.int/publications/i/item/who-sage-values-framework-for-the-allocation-andprioritization-of-covid-19-vaccination

WHO (2020b): WHO SAGE Values framework for the allocation and prioritization of Covid19 Vaccination. World Health Organization. [online] [Retrieved August 31, 2021] Available at: https://apps.who.int/iris/handle/10665/334299 
WHO (2021): Ethical framework for WHO's work in the ACT-Accelerator. World Health Organization. [online] [Retrieved August 26, 2021] Available at: https://www.who.int /publications/i/item/WHO-2019-nCoV-ACT-Accelerator-Ethical_framework-2021.1

ZERTH, J. (2014): Konsumentensouveränität und Gesundheitspolitik: Eine Balance zwischen Selbstverantwortung und Paternalismus? In: List Forum für Wirtschafts- und Finanzpolitik, Sonderheft, pp. 296-321. 